\title{
Detecting an increase in an Endangered huemul Hippocamelus bisulcus population following removal of cattle and cessation of poaching in coastal Patagonia, Chile
}

\author{
Cristóbal Briceño, Leslie A. Knapp, Alejandra Silva, José Paredes \\ Iván Avendaño, Aliro Vargas, Juan Sotomayor and Alejandro R. Vila
}

\begin{abstract}
The conservation of threatened species poses many challenges but through cooperation and pooling of resources, individuals and organizations can work together to achieve better results. Here we describe our experience, working through a governmental and private alliance, studying one of the most threatened mammals in the Southern Cone. The huemul deer Hippocamelus bisulcus, one of two members of the Hippocamelus genus of South America, is endemic to Argentina and Chile and currently inhabits only a small fraction of its former range. Little is known about the huemul because it generally lives in remote areas with a harsh climate and rugged terrain. Using drive counts and fixed width transects over 5 consecutive years (2004-2008) we estimated density and abundance, and examined population changes and social structure, in three coastal huemul populations in the area of the Témpanos and Bernardo fjords of Bernardo O'Higgins National Park, Chile. Our results suggest that synergistic conservation actions, such as cattle removal and poaching control, can lead to the recovery of threatened huemul. The baseline information obtained from our surveys and the lessons learned through this governmental and private alliance will be useful for future monitoring of the huemul in the Patagonian fjords of Chile.
\end{abstract}

Keywords Conservation, deer, Hippocamelus bisulcus, huemul, monitoring, Patagonia, population, protected area

\section{Introduction}

Conservation of threatened species is often a difficult undertaking. In times of increasing competition for

CRISTÓbAl BRICEÑO* (Corresponding author), JuAn Sotomayor and AleJANDRO R. VILA Wildlife Conservation Society Chile, Balmaceda 586, Punta Arenas, Chile. E-mail cristobal.briceno@gmail.com

LESLIE A. KNAPP Primate Immunogenetics and Molecular Ecology Research Group, Department of Archaeology and Anthropology, University of Cambridge, UK

Alejandra Silva, José Paredes, Iván Avendaño and Aliro Vargas Corporación Nacional Forestal, Punta Arenas, Chile

* Also at: Primate Immunogenetics and Molecular Ecology Research Group, Department of Archaeology and Anthropology, University of Cambridge, UK

Received 6 September 2011. Revision requested 13 December 2011.

Accepted 11 January 2012 funding, and with low budgets, in situ research and conservation is especially difficult in remote locations where field activities are expensive. In such cases partnerships can improve cooperation, maximize resources and improve chances of the recovery of species (Clark \& Brunner, 2002).

The huemul deer Hippocamelus bisulcus lives in forest and mixed shrub-grass ecotonal steppe in Argentina and Chile (Cabrera \& Yepes, 1960). The species was originally widespread between latitudes 34 and $54^{\circ} \mathrm{S}$ (Díaz, 2000). However, its range has diminished dramatically since the 19th century and populations are now small and fragmented (Vila et al., 2006). The species is estimated to have declined by $50 \%$ in recent years in Chile (Drouilly, 1983) and its range has shrunk by one-third in Argentina (Serret, 1992). The huemul is categorized as Endangered on both national and global Red Lists (Glade, 1988; Díaz \& Ojeda, 2000; Jiménez et al., 2008).

The current distribution of the huemul is mainly restricted to Nothofagus spp. forests in the Andes and periglacial areas surrounding the continental icecaps in Patagonia (Lopéz et al., 1998; Vila et al., 2010). Although the global population has been estimated to be c. 2,500 (Jiménez et al., 2008), numbers have not been estimated for most populations (Vila et al., 2006). Density has been estimated for nine of the 101 recognized populations (SmithFlueck, 2000) and population trends have been documented for only two populations, in mountainous habitats of Chile (Povilitis, 1998, 2002; CONAF et al., 2009; Corti et al., 2010; Wittmer et al., 2010). The largest remnant huemul populations may be found in coastal areas, where the highest densities have been reported (Povilitis, 1986; Frid, 1994, 2001). These coastal populations are in glacial valleys at sea level. Because of the remoteness and the harshness of their environment, these areas have experienced less human impact than elsewhere (Frid, 1994). This landscape is therefore of critical importance for the conservation of this rare deer.

Research on the huemul in Bernardo O'Higgins National Park in Chile has so far focused on habitat use and social organization (Frid, 1994, 1999, 2001). No population assessments have been conducted methodically in this area. The Park is one of the few places where the huemul can be studied with little human interference and, consequently, this is a key area for understanding the potential effects of 
cattle introduction on the species. It has been suggested that introduction of cattle, on their own or in association with increased hunting, reduced the use of grassland by huemul and increased their wariness in some areas of this Park (Frid, 2001).

To determine abundance, examine any population trend and the deer's social structure after removal of cattle and poaching, we carried out systematic surveys, through a governmental and private alliance, across three periglacial valleys in Bernardo O’Higgins National Park between 2004 and 2008. Here we report our findings and make recommendations for future research on huemul populations in this area.

\section{Study area}

The study was conducted in Bernardo O'Higgins National Park in the Magallanes Region (Fig. 1) of Chilean Patagonia. Topography is complex and rugged, with an extended fjord region, including many islands, peninsulas and channels. This is one of the least densely populated areas in Chile
(Pantoja et al., 2011). The 3.5 million ha Park, created in 1969, lies along the edge of the southern continental icecap and is managed by the Chilean National Forest Service (CONAF). We collected data in the Huemules $\left(3.2 \mathrm{~km}^{2}\right)$, Katraska $\left(5 \mathrm{~km}^{2}\right)$ and Bernardo $\left(13.5 \mathrm{~km}^{2}\right)$ valleys in the area of the Témpanos and Bernardo fjords (Fig. 1).

The climate is cold, wet and influenced by the adjacent ice cap (Carrasco et al., 1998). Precipitation is evenly distributed throughout the year, with an annual mean of $>4,000 \mathrm{~mm}$. Snow falls mostly during June-August. Annual temperatures average $7-8{ }^{\circ} \mathrm{C}$ (Carrasco et al., 1998). The vegetation and topography includes valleys dominated by periglacial grasslands, low-elevation bluffs, grassland-forest ecotones, old-growth forest dominated by Nothofagus spp., and moorlands (Frid, 1994, 2001).

The animal community includes 63 bird species and seven species of amphibious vertebrates (Ortíz \& Iturra, 2011). Mammals include five species of rodents, and carnivores, including culpeo and chilla foxes Pseudalopex spp., wildcats Leopardus spp. and the southern river otter Lontra provocax, and paw prints of the puma Puma concolor

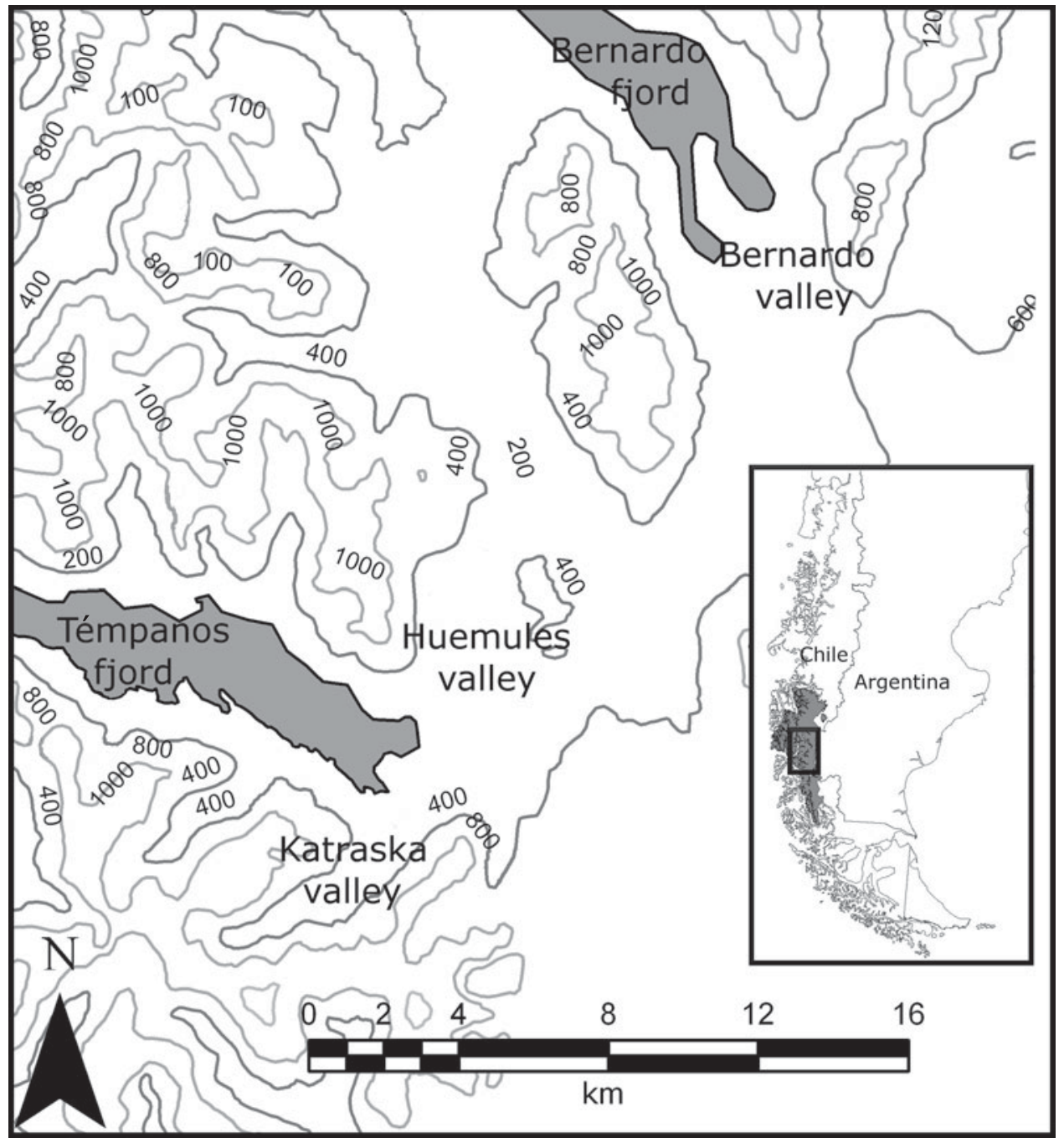

FIG. 1 The study area in Bernardo O’Higgins National Park in Chilean Patagonia, the second largest protected area in South America, showing the locations of the Bernardo, Huemules and Katraska valleys in the area of the Témpanos and Bernardo fjords, and contours in $\mathrm{m}$. The shaded area on the inset indicates the location of the Park, and the rectangle the location of the main map, in Chile. 
have been reported (Rosenfeld, 2000; Wensing, 2005; Guzmán, 2011).

Cattle were illegally introduced into Huemules valley in 1991. Huemul poaching was formerly common in these remote areas because of the lack of infrastructure to enforce conservation laws (Povilitis, 1986; Frid, 1994). Through the joint efforts of CONAF, La Dehesa Zoological Acclimation Center, and the Wildlife Conservation Society, a field station and the permanent presence of park rangers was established at Témpanos fjord in 2002. As a consequence, by 2004 cattle had been removed from the valley. In contrast, Bernardo and Katraska valleys have always been free of cattle. Through collaborative efforts poaching has now mostly been eliminated in the three valleys.

\section{Methods}

From 24 February 2004 to 5 April 2008 huemul deer were surveyed annually in the three valleys. A total of $10-25 \mathrm{~km}$, in 2-4 transects per year, were surveyed in Huemules and Katraska valleys, and $9-38 \mathrm{~km}$, in two transects per year, in Bernardo valley (Table 1). Surveys were conducted between mid spring and early autumn. As the peak birthing season of huemul occurs in spring, the probability of observing newborns and young fawns was highest during this period. Previous studies on habitat use and foraging behaviour have shown that huemul concentrate their activities in valley bottoms and that there is no seasonal movement between spring and early autumn (Frid, 1994, 2001; Van Winden, 2006). Thus, we assume that patterns of habitat use did not influence our sightings of huemul.

Surveys were on foot, with two trained observers on each transect (one resident park ranger plus a visiting researcher), and always in the same direction. For each sighting the date and time, coordinates (with a global positioning system), habitat features, distance to centre of the group, azimuth (using transect bearing as reference), number of individuals per group and age class of individuals (adults or juveniles of each sex, fawn or undetermined) were recorded.

In the open Huemules valley, observers on each transect began the survey together, communicated with hand-held radios, remained within sight of each other and travelled at approximately the same speed to avoid counting the same animals more than once. Thus, drive counts covered the whole valley, including the forest edge on both sides of the area. Huemul use the adjacent forests only during the winter (Frid, 1994), and most tend to remain quiet when they are sighted. We therefore assumed that most huemul in the

TABLE 1 Numbers of huemul Hippocamelus bisulcus counted in surveys in Bernardo O'Higgins National Park (Fig. 1) during 2004-2008, with female : male and fawn : female ratios, and density estimates.

\begin{tabular}{|c|c|c|c|c|c|c|c|c|}
\hline \multirow{2}{*}{$\begin{array}{l}\text { Survey date } \\
\text { (by valley) }\end{array}$} & \multirow{2}{*}{$\begin{array}{l}\text { Distance } \\
\text { surveyed }(\mathrm{km})\end{array}$} & \multicolumn{4}{|c|}{ Number counted } & \multirow{2}{*}{$\begin{array}{l}\text { Female: male } \\
\text { ratio }\end{array}$} & \multirow{2}{*}{$\begin{array}{l}\text { Fawn : female } \\
\text { ratio }\end{array}$} & \multirow[b]{2}{*}{ Density } \\
\hline & & Males & Females & Fawns & Total $^{\star}$ & & & \\
\hline \multicolumn{9}{|l|}{ Huemules } \\
\hline Feb. 2004 & 9.90 & 1 & 1 & 0 & 2 & 0.50 & 0.00 & 0.67 \\
\hline Nov. 2004 & 10.67 & 2 & 1 & 0 & 3 & 0.33 & 0.00 & 0.94 \\
\hline Apr. 2006 & 18.09 & 2 & 4 & 1 & 7 & 0.57 & 0.33 & 2.19 \\
\hline Apr. 2007 & 19.48 & 3 & 3 & 0 & 6 & 0.50 & 0.00 & 1.88 \\
\hline Nov. 2007 & 10.67 & 2 & 3 & 0 & 5 & 0.60 & 0.00 & 1.56 \\
\hline Apr. 2008 & 10.67 & 4 & 3 & 1 & 8 & 0.38 & 0.33 & 2.50 \\
\hline$M e a n \pm S E$ & & & & & & $0.48 \pm 0.04$ & $0.11 \pm 0.07$ & $1.62 \pm 0.29$ \\
\hline \multicolumn{9}{|l|}{ Katraska } \\
\hline Feb. 2004 & 20.40 & 1 & 4 & 2 & 7 & 0.57 & 0.67 & 1.72 \\
\hline Nov. 2004 & 24.95 & 6 & 11 & 0 & 17 & 0.65 & 0.00 & 3.41 \\
\hline Apr. 2006 & 21.94 & 6 & 12 & 4 & 22 & 0.55 & 0.44 & 5.01 \\
\hline Apr. 2007 & 10.29 & 8 & 17 & 4 & 29 & 0.59 & 0.29 & 9.39 \\
\hline Nov. 2007 & 24.95 & 2 & 4 & 1 & 7 & 0.57 & 0.33 & 1.40 \\
\hline Apr. 2008 & 11.02 & 0 & 6 & 1 & 9 & 0.67 & 0.25 & 4.08 \\
\hline$M e a n \pm S E$ & & & & & & $0.60 \pm 0.02$ & $0.33 \pm 0.09$ & $4.17 \pm 1.19$ \\
\hline \multicolumn{9}{|l|}{ Bernardo } \\
\hline Feb. 2004 & 8.60 & 4 & 13 & 4 & 29 & 0.45 & 0.31 & 7.49 \\
\hline Nov. 2004 & 38.33 & 10 & 18 & 2 & 31 & 0.58 & 0.18 & 2.70 \\
\hline Feb. 2005 & 24.38 & 18 & 28 & 6 & 57 & 0.49 & 0.35 & 7.79 \\
\hline Apr. 2006 & 16.31 & 15 & 30 & 10 & 62 & 0.48 & 0.48 & 12.67 \\
\hline Apr. 2007 & 28.08 & 28 & 29 & 9 & 71 & 0.41 & 0.33 & 8.43 \\
\hline Apr. 2008 & 25.06 & 21 & 37 & 2 & 60 & 0.62 & 0.06 & 7.60 \\
\hline$M e a n \pm S E$ & & & & & & $0.50 \pm 0.03$ & $0.29 \pm 0.06$ & $7.78 \pm 1.30$ \\
\hline
\end{tabular}

${ }^{\star}$ Includes juveniles (included in counts of males and females) and unidentified individuals 
valley during the survey would be detected. In contrast, Katraska, although locally referred to as a valley, is more accurately defined as a ravine dominated by rugged and steep terrain. Bernardo valley has areas of flat valley and rugged terrain. For the latter two valleys fixed-width transects of 200 and $300 \mathrm{~m}$ wide, respectively, were used and only part of the valleys were surveyed.

The potential association between huemul counts and sampling effort (measured as km surveyed) was examined with a non-parametric Spearman rank correlation (Zar, 1996). Huemul densities were estimated by counting the number of individuals on transects and dividing this by the surveyed area (transects in Bernardo and Katraska valleys and the total valley area in Huemules valley). Abundance in each valley was estimated by extrapolation of the observed density to the whole valley area. Although we collected data for the calculation of detection probabilities, this was not feasible because the low number of huemul sightings per transect violated the assumptions of the model (Buckland et al., 2001). The exponential rate of increase ( $r$ ) was calculated as the slope of the regression line fitted to natural logarithms of the yearly estimates of abundance obtained for each study area (Caughley \& Gunn, 1996). When we had more than one abundance estimate per year, we used the annual mean value. We also calculated the finite rate of increase $(\lambda)$, adjusted for 1 year interval, using the counts of huemul in each valley.

Female : male and fawn : adult female ratios were calculated. As no differences in group sizes were observed between years or months of the surveys in each valley, we pooled the data obtained per site between years. We analysed differences in group size across study sites using a Kruskal-Wallis H-test. Differences in densities, female : male and fawn : female ratios across study sites were investigated with a one-way ANOVA. We compared the estimated age structure among valleys using a $\chi^{2}$ test (Zar, 1996). Data for different years were pooled and juvenile females and males were combined to increase sample size in each frequency cell of the analysis.

\section{Results}

We surveyed a total of $334 \mathrm{~km}$ of transects from February 2004 to April 2008, covering an estimated total area of 86.6 $\mathrm{km}^{2}$ in the three valleys combined. Survey results were highly variable between years and sites (Table 1). The counts of huemul in Huemules valley varied between two in 2004 and eight in 2008, in Katraska valley between seven and 29 in 2004 and 2007, respectively, and in Bernardo valley 29 and 71 in 2004 and 2007, respectively. The number of sightings did not correlate with the length of transects: Huemules $(r=0.58, \quad \mathrm{P}>0.05), \quad$ Katraska $\quad(r=-0.40$, $\mathrm{P}>0.05)$, and Bernardo $(r=0.26, \mathrm{P}>0.05)$. Thus, an increase or decrease in sampling effort did not reflect an increase or decrease in the observed animals (Table 1).

The estimated mean densities varied significantly between sites $\left(F_{2,15}=9.07, \mathrm{P}<0.05\right)$. The density in Bernardo valley was higher than in the other two valleys (Table 1 ). The mean density for the three valleys combined was $4.52 \pm \mathrm{SE}$ $0.83 \mathrm{~km}^{-2}(\mathrm{n}=18)$.

Although there were fluctuations in annual estimates of abundance for each study site, there was a general increase (Fig. 2). The exponential rates of increase were positive in all three valleys (Huemules, $r=0.26$; Katraska, $r=0.09$; Bernardo, $r=0.14)$. The estimated values of $\lambda$ also indicated population increases (Huemules, $\lambda=1.41$; Katraska, $\lambda=1.06$; Bernardo, $\lambda=1.19$ ).

Group sizes did not differ significantly among sites $(\mathrm{H}=5.02, \mathrm{P}>0.05)$ but mean group size was higher in Bernardo (2.54 \pm SE 0.2, range $1-14, n=122)$ than in Katraska (2.02 \pm SE 0.16, range $1-5, \mathrm{n}=45)$ and Huemules valleys $(1.48 \pm$ SE 0.22 , range $1-5, n=21)$.

The overall mean sex ratio, including adults and juveniles, was slightly skewed towards females (mean $=0.53 \pm$ SE 0.02, $\mathrm{n}=18$ ). This trend was more marked for the adult sex ratio $($ mean $=0.60 \pm \mathrm{SE} 0.03, \mathrm{n}=18)$. Female to male ratio was not significantly different between valleys $\left(F_{2,15}=3.53\right.$, $\mathrm{P}>0.05$ ) but a higher female : male ratio was observed in Katraska valley (Table 1). The overall fawn: adult female ratio for the study period and the three study sites was $0.24 \pm$ SE $0.05(n=18)$. There were no differences across valleys in this ratio $\left(F_{2,15}=2.43, \mathrm{P}>0.05\right)$ but the lowest value was in Huemules valley (Table 1).

Adult males and females together comprised the majority of the population (Table 1). The lowest percentage of fawns was recorded in Huemules valley and the highest in

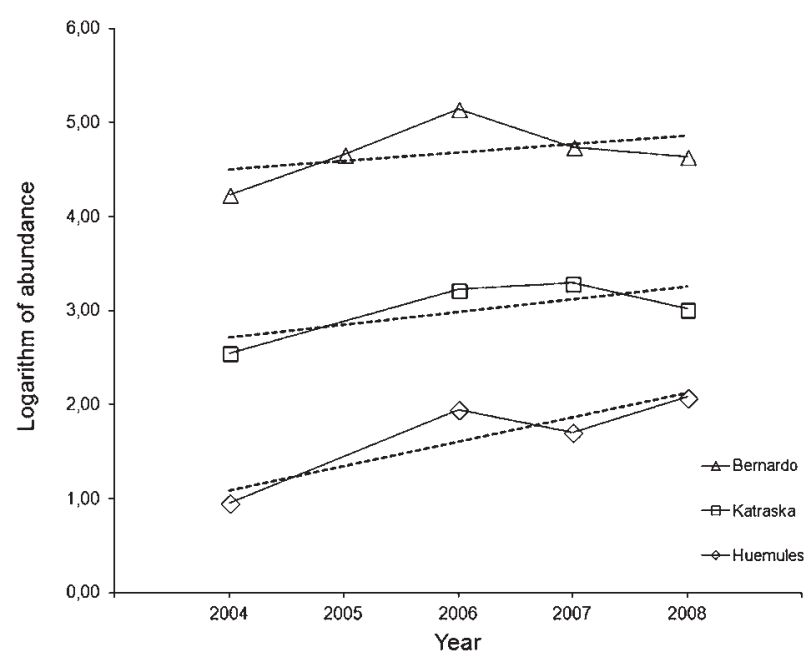

FIG. 2 Logarithm of abundance of the huemul Hippocamelus bisulcus in the three surveyed valleys in Bernardo O'Higgins National Park (Fig. 1) from 2004 to 2008. Each dashed line is the regression line fitted to the natural logarithms of the annual estimates of abundance. 
Katraska valley (Table 1). There were, however, no differences in age structure between valleys $\left(\chi^{2}=5.50, \mathrm{df}=6\right.$, $\mathrm{P}>0.05)$.

\section{Discussion}

The huemul deer lives mainly at low-densities in remote, forested and steep terrains, and thus it is difficult to estimate the size of populations. In Chile the huemul population has been reported to be declining in Nevados de Chillán (Povilitis, 1998, 2002) but stable at Lago Cochrane (Corti et al., 2010). These, and the present study, are the only data available for the species in Chile, and our surveys provide the only data for coastal populations.

In 1990, before cattle introduction, Frid (2001) observed just 1-3 of the seven huemul then known in Huemules valley. After introduction of cattle in 1995 huemul were not observed in the valley but 6-7 individuals were recorded on rocky slopes at the lowest forest edges (Frid, 2001). Although his surveys were of changes in habitat use, Frid estimated there was a minimum of 22 huemul in 1990 but only seven in 1995. These fell to four and three in 2000 and 2001, respectively, when cattle density increased (Rosenfeld, 2000; Acosta, 2001). Wensing (2005) reported three resident huemul in 2003-2004. Overall, our 5 years of monitoring suggest a trend of increasing abundance in the Huemules valley following cattle removal and the cessation of poaching. The estimated exponential and finite rates of increase support this. Considering the low fawn : female ratio in this valley it is likely that this increase is sustained by immigration. Our most recent count in this valley suggests that the number of resident huemul is now the same as recorded by Frid (2001) before cattle introduction.

Previous counts in Bernardo valley were of 60-75 individuals (Frid, 1999; Wensing, 2005), similar to our count in 2008. Bernardo valley has the highest mean density of huemul, perhaps because of the isolation of the valley from human activities compared to Témpanos fjord and the Katraska and Huemules valleys, which can be accessed from the hamlet of Puerto Edén.

Huemul densities could also be influenced by habitat availability. Katraska and Huemules are smaller valleys than Bernardo and habitat size and/or quality could be limiting factors. The mean density for the three valleys $\left(4.52 \mathrm{~km}^{-2}\right)$ was higher than those reported $\left(0.02-1.79 \mathrm{~km}^{-2}\right)$ for populations in the interior mountainous range of the species (Smith-Flueck, 2000; Guineo et al., 2008; Jiménez et al., 2008; Corti et al., 2010). The present distribution of the huemul extends along a narrow 1,900-km long strip: a latitudinal span that includes highly variable conditions of elevation, precipitation and vegetation (Vila et al., 2010).

Sex ratios in Katraska were biased toward females, as in the huemul population at Lago Cochrane (Corti et al., 2010). Clutton-Brock et al. (2002) also reported similar sex ratios for red deer in Scotland. Male ungulates have higher mortality because of confrontations with other males, territorial defence, higher nutritional requirements and/or exposure to predators (Clutton-Brock et al., 1985; Berger, 1991; Main et al., 1996). Katraska is the steepest and most rugged of the three valleys we studied. This type of terrain has been described as the preferred protected habitat for females and fawns (Frid, 1999). Limited predator access could explain the higher female:male ratio. The highest fawn:female ratio and percentage of fawns was also observed in Katraska, further indicating the potential importance of rugged terrain for the species. Despite the higher fawn : female ratio, population size seems to be stable instead of increasing, suggesting that these fawns are not reaching adulthood within this population. As we have not found any evidence of unusually high mortality, we believe that there may be some level of interconnectivity among valleys, with migratory movements between populations. We consider that the population in Katraska valley could have high conservation importance at a local scale because of the shelter its rugged terrain offers to fawns. Bernardo is the site most exposed to predation but we would expect that aggregation provides some benefit as an anti-predation strategy (Jarman, 1974). Frid (1999) observed that group size increased with distance from rocky slopes in this valley, suggesting that the risk of predation is lower on rocky slopes than in valley-bottom habitats. We observed larger group sizes in the Bernardo than in the Katraska and Huemules valleys.

Corti et al. (2010) reported predation of huemul by puma and introduced dogs. Culpeo fox Pseudalopex culpaeus was also a common predator of fawns at this study site at Lago Cochrane. Culpeo are known to predate prey that are of similar size to adult huemul (Novaro et al., 2009). Wensing (2005) reported tracks of puma in the Huemules and Bernardo valleys but no additional evidence has been found when rangers have been permanently present in the Park, including when cattle could have attracted puma. However, in Huemules valley culpeo fox have been observed to attack huemul that had infected foot injuries (J. Sotomayor \& J. Paredes, pers. comms). Predation by culpeo fox on huemul has not been reported in Bernardo and Katraska valleys, and foot infections have not been observed there. Considering how these infections seem to reduce the movement of huemul, predators could increase mortality in static and vulnerable individuals. The culpeo fox diet is supplemented by food from the sea in coastal environments (Gomez et al., 2010), and higher densities of carnivores have been described for coastal areas (Rose \& Polis, 1998). Consequently, we would expect higher densities of culpeo fox in our study site compared to inland habitats. Given the opportunistic behaviour of foxes, vulnerable deer could also attract them and this could explain the low number of fawns recorded in the Huemules valley. 
Our counts and abundance estimates of the huemul varied between years within sites and our results need to be interpreted cautiously because three factors may influence the abundance of this Endangered deer. Firstly, individuals of these populations may be migratory. Frid (1999) and Wensing (2005) noted that Huemules valley may be a transitory region for dispersal and for temporary residence of solitary individuals as this valley is connected with Bernardo fjord by other valleys. Secondly, preferential habitat use could affect detection probabilities by restricting the number of animals using open areas. Although huemul use forest during the winter in our study area (Frid, 1994, 2001), populations living within forests have been reported in other parts of Bernardo O'Higgins National Park (Frid, 1999; Rosenfeld, 2000). Thirdly, although we surveyed using distance sampling methodology (Buckland et al., 2001) we could not analyse these data using this technique because the number of huemul sightings per transect were too few. If permanent transects could be established, and surveyed several times in a season, and if the population is stable within a sampling period, all data from repeated visits would be pooled into a single transect (Buckland et al., 2001). Wittmer et al. (2010) described an alternative approach involving estimation of detection probabilities and determination of the accuracy of counts in a well studied and accessible huemul population. However, this technique would be difficult to use in most of our study area as only Huemules valley has facilities and personnel to monitor marked animals on a regular basis.

In summary, to assess the effectiveness of the conservation interventions for huemul in part of the remote Bernardo O'Higgins National Park we first evaluated how the removal of cattle and elimination of poaching changed the threats to the species, and we then monitored huemul abundance as an indicator of recovery (Salzer \& Salafsky, 2006). This collaboration (as recommended for monitoring; Lindenmayer \& Likens, 2010) between scientists and wildlife rangers resulted in an effective and regular monitoring programme. Such close communication between stakeholders is vital for long-term success of conservation programmes (Stem et al., 2005). Our estimates of the density and abundance of the three studied populations of huemul indicate they have the potential to maintain their numbers if undisturbed. This study provides an example of a successful governmental-private collaboration, at a local scale, for the conservation of this Endangered deer in Patagonia.

\section{Acknowledgements}

This project would not have been possible without support from CONAF. We thank Jorge Pérez, Germán Coronado, Guillermo Igor, Víctor Muñoz, Manuel Barrientos, Héctor Galaz, Marcela Uhart, Paola Etchegaray, Ricardo Muza,
Mauricio Rosenfeld, Adrian Hughes and Claudio Moraga for their assistance. We also thank Molly Fox, Heiko Wittmer and an anonymous reviewer for their helpful suggestions. Financial support was provided by Michel Durand, Weeden Foundation, Agnes Gundt, Wuppertal Zoo, the Wildlife Conservation Society and Idea Wild.

\section{References}

Acost A, G. (2001) Informe prospección de huemules sectores Fiordo Témpanos, Bahía Elizabet y Glaciar Pío. Parque Nacional Bernardo O’Higgins-XII Región. Unpublished Report. CONAF, Santiago, Chile.

Berger, J. (1991) Pregnancy incentives, predation constraints and habitat shifts: experimental and field evidence for wild bighorn sheep. Animal Behaviour, 41, 61-77.

Buckland, S.T., Anderson, D.R., Burnham, K.P., LaAke, J.L., Borchers, D.L. \& Thomas, L. (2001) Introduction to Distance Sampling: Estimating Abundance of Biological Populations. Oxford University Press, Oxford, UK.

Cabrera, A. \& Yepes, J. (1960) Mamíferos Sudamericanos, 2nd edition. Ediar, Buenos Aires, Argentina.

Carrasco, J.F., Casassa, G. \& Rivera, A. (1998) Climatología actual del Campo de Hielo Sur y posibles cambios por el incremento del efecto invernadero. Anales del Instituto de la Patagonia. Serie Ciencias Naturales, 26, 119-128.

Caughley, G. \& Gunn, A. (1996) Conservation Biology in Theory and Practice. Blackwell Science, Massachusetts, USA.

Clark, T.W. \& BRUnNer, R.D. (2002) Making partnerships work in endangered species conservation: an introduction to the decision process. Endangered Species Update, 19, 74-80.

Clutton-Brock, T.H., Coulson, T.N., Milner-Gulland, E.J., Thomson, D. \& Armstrong, H.M. (2002) Sex differences in emigration and mortality affect optimal management of deer populations. Nature, 415, 633-637.

Clutton-Brock, T.H., Major, M. \& Guinness, F.E. (1985) Population regulation in male and female red deer. Journal of Animal Ecology, 54, 831-846.

Corporación Nacional Forestal, Servicio Agrícola y Ganadero \& Corporación Nacional del Medio Ambiente (2009) Plan Nacional de Conservación del Huemul (Hippocamelus bisulcus, Molina 1782) en Chile, 2008-2012. In Taller Participativo para la Elaboración del Plan (ed. D. Aldrigde), pp. 1-50. Puerto Fuy, Agosto 2007, Chile.

Corti, P., Wittmer, H.U. \& Festa-Bianchet, M. (2010) Dynamics of a small population of endangered huemul deer (Hippocamelus bisulcus) in Chilean Patagonia. Journal of Mammalogy, 91, 690-697.

Díaz, G.B. \& OJEDA, R.A. (2000) Libro Rojo: Mamíferos amenazados de la Argentina. Sociedad Argentina para el Estudio de los Mamíferos, Mendoza, Argentina.

Díaz, N.I. (2000) El huemul (Hippocamelus bisulcus Molina, 1782): una perspectiva histórica. In El huemul Patagónico, un misterioso cérvido al borde de la extinción (eds N.I. Díaz \& J.A. Smith-Flueck), pp. 1-32. Literature of Latin America, Buenos Aires, Argentina.

Droullly, P. (1983) Recopilación de antecedentes biológicos y ecológicos del huemul chileno y consideraciones sobre su manejo. Boletín Técnico 5 CONAF. Unpublished Report. CONAF, Santiago, Chile.

FRID, A. (1994) Observations on habitat use and social organization of a huemul (Hippocamelus bisulcus) coastal population in Chile. Biological Conservation, 67, 13-19. 
Frid, A. (1999) Huemul (Hippocamelus bisulcus) sociality at a periglacial site: sexual aggregation and habitat effects on group size. Canadian Journal of Zoology, 77, 1083-1091.

Frid, A. (2001) Habitat use by endangered huemul (Hippocamelus bisulcus): cattle, snow, and the problem of multiple causes. Biological Conservation, 100, 261-267.

Glade, A. (1988) Libro rojo de los vertebrados terrestres de Chile, and edition. CONAF, Santiago, Chile.

Gomez, J.J., Gozzi, A.C., Macdonald, D.W., Gallo, E., Centrón, D. \& Cassini, M.H. (2010) Interactions of exotic and native carnivores in an ecotone, the coast of the Beagle Channel, Argentina. Polar Biology, 33, 1371-1378.

Guineo, O., Guineo Garay, R. \& Garay, G. (2008) Conociendo al huemul en Torres del Paine. La Prensa Austral, Punta Arenas, Chile.

GuZmán, J. (2011) Rodents. In Bernardo O’ Higgins National Park (eds J.C. Aravena, G. Vela-Ruiz, R. Villa-Martínez, E. Domínguez, C. Aldea, J. Sanhueza et al.), pp. 77-79. CONAF, CORFO \& CEQUA, Punta Arenas, Chile.

JARMAN, P.J. (1974) The social organization of antelope in relation to their ecology. Behaviour, 48, 216-267.

Jiménez, J., Guineo, G., Corti, P., Smith, J.A., Flueck, W., Vila, A. et al. (2008) Hippocamelus bisulcus. In 2008 IUCN Red List of Threatened Species. IUCN, Gland, Switzerland. Http://www. iucnredlist.org [accessed 5 November 2011].

Lindenmayer, D.B. \& Likens, G.E. (2010) The science and application of ecological monitoring. Biological Conservation, $143,1317-1328$.

López, R., Serret, A., Fáundez, R. \& Palé, G. (1998) Estado del conocimiento actual de la distribución del huemul (Hippocamelus bisulcus, Cervidae) en Argentina y Chile. FVSA, WWF \& CODEFF, Concepción, Chile.

Main, M.B., Weckerly, F.L. \& Bleich, V.C. (1996) Sexual segregation in ungulates: new directions for research. Journal of Mammalogy, 77, 449-461.

Novaro, A.J., Moraga, C.A., Briceño, C., Funes, M.C. \& Marino, A. (2009) First records of culpeo (Lycalopex culpaeus) attacks and cooperative defense by guanacos (Lama guanicoe). Mammalia, 73, 148-150.

Ortíz, J.C. \& Iturra, M. (2011) Amphibians. In Bernardo O'Higgins National Park (eds J.C. Aravena, G. Vela-Ruiz, R. Villa-Martínez, E. Domínguez, C. Aldea, J. Sanhueza et al.), pp. 84-87. CONAF, CORFO \& CEQUA, Punta Arenas, Chile.

Pantoja, S., Iriarte, J.L. \& Daneri, G. (2011) Oceanography of the Chilean Patagonia. Continental Shelf Research, 31, 149-153.

Povilitis, A. (1986) Huemuls in areas adjacent to glaciers in southern Chile. Mountain Research and Development, 6, 273-275.

Povilitis, A. (1998) Characteristics and conservation of a fragmented population of huemul Hippocamelus bisulcus in central Chile. Biological Conservation, 86, 97-104.

Povilitis, A. (2002) El estado actual del huemul (Hippocamelus bisulcus) en Chile Central. Gayana, 66, 59-68.

Rose, M.D. \& Polis, G.A. (1998) The distribution and abundance of coyotes: the effects of allochthonous food subsidies from the sea. Ecology, 79, 998-1007.
Rosenfeld, M. (2000) Guía de manejo sector norte Parque Nacional Bernardo O'Higgins. CONAF-Gobierno Regional XII región, Tomos I y II. Unpublished Report. CONAF, Punta Arenas, Chile.

SAlzer, D. \& SALAFSKY, N. (2006) Allocating resources between taking action, assessing status, and measuring effectiveness of conservation actions. Natural Areas Journal, 26, 310-316.

Serret, A. (1992) Distribución actual del huemul (Hippocamelus bisulcus) en la República Argentina. Boletín Técnico No. 1. FVSA, Buenos Aires, Argentina.

Smith-Flueck, J.A. (2000) La situación actual del Huemul Patagónico. In El huemul Patagónico, un misterioso cérvido al borde de la extinción (eds N.I. Díaz \& J.A. Smith-Flueck), pp. 67-146. Literature of Latin America, Buenos Aires, Argentina.

Stem, C., Margoluis, R., Salafsky, N. \& Brown, M. (2005) Monitoring and evaluation in conservation: a review of trends and approaches. Conservation Biology, 19, 295-309.

VAn Winden, J. (2006) Diet and habitat of the huemul (Hippocamelus bisulcus) in Bernardo O' Higgins National Park, Chile. MSc thesis. Utrecht University, Utrecht, The Netherlands.

Vila, A.R., López, R., Pastore, H., Faúndez, R. \& Serret, A. (2006) Current distribution and conservation of the huemul (Hippocamelus bisulcus) in Argentina and Chile. Mastozoología Neotropical, 13, 263-269.

Vila, A.R., Saucedo Gálvez, C.E., Aldridge, D., Ramilo, E. \& Corti GonzÁlez, P. (2010) South Andean Huemul (Hippocamelus bisulcus, Molina 1782). In Neotropical Cervidology: Biology and Medicine of Latin American Deer (eds J.M. Barbanti Duarte \& S. González) pp. 89-10o. FUNEP-IUCN, Sao Paulo, Brazil.

Wensing, D.A. (2005) Conservation study of the huemul (Hippocamelus bisulcus) within the Bernardo O'Higgins National Park, Chile. MSc thesis. Utrecht University, Utrecht, The Netherlands.

Wittmer, H.U., Corti, P., Saucedo, C. \& Galáz, J.L. (2010) Learning to count: adapting population monitoring for Endangered huemul deer Hippocamelus bisulcus to meet conservation objectives. Oryx, 44, 516-522.

ZAR, J.H. (1996) Biostatistical Analysis, 3rd edition. Prentice Hall, New Jersey, USA.

\section{Biographical sketches}

CRISTÓBAL BRICEÑO is a veterinarian interested in conservation of threatened species and their habitats. He has been working with endemic South American mammals for the last 10 years. Leslie A. KNAP P studies the ecology, genetics and behaviour of a wide range of mammals. Alejandra Silva coordinates the Austral Task Force of the Huemul National Plan in Chile. José Paredes, IVÁN AVENDAÑO and ALIRO VARGAS are park rangers, and have worked at Témpanos Field Station since 2004. JUAN SOTOMAYOR was in charge of Témpanos Station and formerly worked as a park ranger coordinator in Karukinka Natural Park, Tierra del Fuego. A LE J A N D RO VILA has worked on the conservation of pampas deer and huemul and on conservation planning in Patagonia since 2000. 